\title{
FORMAÇÃO PROFISSIONAL NA CONSTRUÇÃO DA IDENTIDADE DOCENTE
}

\author{
PROFESSIONAL TRAINING IN THE CONSTRUCTION OF TEACHING \\ IDENTITY
}

\author{
Beatriz Pereira dos Santos \\ Especialista em Psicopedagogia \\ Universidade Cidade de São Paulo -UNICID \\ São Paulo, SP - Brasil. \\ beatriz.pereira@sme.prefeitura.sp.gov.br \\ Ida Carneiro Martins \\ Doutorado em Educação \\ Universidade Cidade de São Paulo - UNICID. \\ São Paulo, São Paulo, Brasil. \\ tita.carneiromartins@gmail.com \\ Roberto Gimenez \\ Doutorado em Educação Física \\ Universidade Cidade de São Paulo - UNICID. \\ São Paulo, São Paulo, Brasil. \\ roberto.gimenez@unicid.edu.br
}

\begin{abstract}
Resumo: O artigo tem como objetivo discutir a identidade docente construída ao longo da formação inicial, entendendo esse processo como fundamental para a prática pedagógica futura. Questões nortearam este trabalho, tais como: Qual a condição da escolha para se tornar professor? Como a identidade docente é construída? A natureza da pesquisa é qualitativa e realizada a partir de referenciais bibliográficos que embasaram os seus pressupostos, assim como Gimenez e Da Silva (2018); Tardif (2001); Sgadari Passeggi (2011); Furlanetto (2018), que partilham a ideia de que o contexto em que o aluno está inserido acaba por interferir em suas decisões frente aos grupos sociais com os quais convive e interage. Conclui-se que a construção da identidade docente se inicia na escolha, que depende da formação inicial e continuada. Em especial, a primeira requer a revisão de suas matrizes para que se aproximem da realidade e abarquem a complexidade da ação do professor.
\end{abstract}

Palavras-chave: formação profissional; identidade docente; formação continuada.

Abstract: The article aims to discuss and reflect on the teaching identity built during the initial training, understanding this qualification as a disseminator of knowledge for future pedagogical practice. Questions guided this work, such as: What is the condition of the choice to become a teacher? How is the teaching identity constructed? The nature of the research is qualitative and based on bibliographic references that supported its assumptions, as well as Gimenez \& Da Silva (2018); Tardif (2001); Sgadari Passeggi (2011); Furlanetto (2018), who share the idea that the context in which the student is inserted ends up interfering in his decisions in front of the social groups he lives and interacts with. Concluding that the construction of the teaching identity begins in the choice, which depend on the initial and continued formation, in particular, the first requires the revision of their matrices in order to approach the reality and embrace the complexity of the teacher's action.

Keywords: professional qualification; teaching identity; continuing teacher education.

Para citar - ABNT NBR 6023:2018

SANTOS, Beatriz Pereira; MARTINS, Ida Carneiro; GIMENEZ, Roberto. Formação profissional na construção da identidade docente. Cadernos de Pós-graduação, São Paulo, v. 20, n. 2, p. 17-27, jul./dez. 2021. Disponível em: https://doi.org/10.5585/cpg.v20n2.20160. 


\section{Introdução}

A construção da identidade profissional é um processo multifacetado e constitui-se a partir das vivências que o estudante teve ao longo de sua vida - antes da escolha profissional, durante o processo de formação inicial e continuada, e na ação docente -, as quais fomentam as concepções acerca da profissão. É fato que as vivências e as concepções do grupo social do qual o sujeito faz parte são fundamentais à construção de sua identidade docente, pois envolvem inúmeros elementos, tais como a construção de valores e as experiências vividas, os quais são condizentes com as suas crenças. A formação inicial, todavia, é muito relevante neste processo.

As autoras Furlanetto (2018) e Sgadari Passeggi (2011) discutem que a construção dos saberes docentes está alinhada com o percurso pessoal, a formação inicial, a sua profissionalização, dentre outras questões, que permitem ao docente pensar sobre suas escolhas e determinações, pois refletem a historização de sua carreira.

Outra questão que influencia fortemente a construção da identidade profissional é o prestígio social que se atribui à profissão, o que não é diferente em relação à identidade do professor. Nesse caso específico, a relação escola-família é muito relevante. Ao longo do tempo, essa relação sofreu inúmeras transformações e, gradativamente, o seu tensionamento fez com que a docência fosse perdendo a notoriedade.

Segundo Nóvoa (1999), a história da educação e da profissão docente data da segunda metade do século XVIII, e o movimento em torno do controle da igreja perante a instrução foi crucial para o desenvolvimento de um ensino com características religiosas, no qual colocavam-se crenças e valores como sistema de educação. No século XIX, ainda que com resquícios religiosos, a profissão começa a ascender e a constituir-se de um grupo que encara o ofício como ocupação principal, respondendo ao Estado que estabelecia o seu controle.

Lopes (2015) contribui à discussão enfatizando a relevância que tiveram as Escolas Normais na formação de professores, no Brasil, durante o século XIX, mas ressalta que ainda estava presente a concepção que se verificava desde o século XVIII, ou seja, a separação do currículo acadêmico e da prática docente, o que colocava o professor como um mero instrutor técnico. Apesar dos esforços, as Escolas Normais não conseguiram contemplar a formação profissional, haja vista os movimentos sociais e políticos, juntamente com a reforma em prol da instrução na qualidade de ensino ocorridos em meados do século XX, o que resultou em sua substituição pela habilitação em Magistério.

A partir de 1982, a formação profissional começa a ser institucionalizada em espaços específicos, que redimensionam a formação de professores com a criação do projeto relativo ao Centro Específico de Formação e Aperfeiçoamento do Magistério - CEFAM. Essa proposta veio 
para amenizar rupturas nos problemas de formação, mas alcançou pouco aproveitamento, o que enfraqueceu a proposta, e os cursos foram extintos no início do século XX (LOPES, 2015).

Tanuri (2000) afirma que a existência de lacunas no processo de formação de professores coloca em evidência estudos que trazem um olhar crítico que se acentua com a Lei de Diretrizes e Bases da Educação Nacional - LDB, em 1996.

Apesar dos primeiros indícios de formação não estarem voltados para o professor em si, mas para o progresso da Escola Normal, quem lecionava deveria ter o mínimo para a titulação de professor, como ler, escrever e recitar orações de cor, uma vez que as ideologias cristãs estavam bem presentes naquele momento, sendo avaliados por um exame que tinha poucos candidatos e cujo resultado era sempre positivo.

A autora ainda destaca que os programas de formação e a duração do curso foram se ajustando, com disciplinas pedagógicas em um primeiro momento, estudos envolvendo as crianças em um segundo momento e, por último, as relações sociais ligadas ao meio, modificando-se até a inserção do curso de Pedagogia, que veio em um sistema de 3+1, ou seja, três anos de formação com disciplinas de fundamentos da educação e um ano de didática para o licenciado.

Com a necessidade de ampliar os conhecimentos em torno dos processos educativos e a qualificação para o ensino - de modo a valorizar a profissão docente e, consequentemente, a aprendizagem do aluno - e, ainda, com as exigências da sociedade, a formação por meio do Magistério já não era suficiente e não dava conta da demanda. Assim, com a LDB (BRASIL, 1996), passou-se a exigir o curso de Pedagogia em nível universitário para lecionar e qualificar a atuação de ambos.

Art. 62. A formação de docentes para atuar na educação básica far-se-á em nível superior, em curso de licenciatura plena, admitida, como formação mínima para o exercício do magistério na educação infantil e nos cinco primeiros anos do ensino fundamental, a oferecida em nível médio, na modalidade normal. (BRASIL, 1996, p. 24).

As exigências quanto à formação fizeram os professores irem em busca das universidades, o que determinou, para a carreira docente, uma mudança de visão torno da construção da identidade desses profissionais, pois, historicamente, a opção pelo magistério era feita, em geral, em decorrência da base familiar que se constituía e a relevância dada à função de professor. Os ajustes também contemplaram os currículos das universidades, que passaram a se readequar para conseguirem, assim, atender ao que era necessário para a formação docente plena.

Gimenez e Da Silva (2018) ressaltam que, na formação docente, o distanciamento entre teoria e prática tem mostrado uma ruptura nos cursos que não são condizentes com o contexto atuante, caracterizando inúmeras expectativas fora da realidade. 
Baseando-se nas ideias aqui expostas, o objetivo deste trabalho é entender a constituição da formação profissional inicial do professor como fator de suma importância para a construção da identidade docente em sua carreira.

Neste artigo, portanto, buscou-se literatura condizente com a proposta, de desafios perante a profissão docente, considerando seus dilemas, percalços e a trajetória da construção identitária.

\section{Escolhas e dilemas da profissão}

Estudos de Paniago e Sarmento (2015) mostram que a escolha pela docência se dá, principalmente, pelo baixo custo do curso inicial, pelo tempo curto dos cursos de licenciaturas, pela oportunidade no mercado de trabalho e pela estabilidade. Tais questões colocam em discussão a escolha profissional que o estudante faz, o que acaba sendo confrontado nas situações de estágio supervisionado, quando há o contato com a realidade docente.

Sgadari Passeggi (2011) elucida que as escolhas realizadas pelo sujeito são influenciadas pelo seu contexto biográfico e ressalta que toda a experiência de vida tem relação com a formação humana de forma ativa, à qual se vincula com memórias que produzem saberes. Contudo, conhecer-se como sujeito histórico, pertencente a um local de origem, traz à tona dilemas que podem interferir nas escolhas de vida.

\footnotetext{
A formação, quando adota a mirada reflexiva sobre a experiência vivida, em nenhum momento, deve ser entendida como uma (trans)formação sem crises. Ela adota, ao contrário, na perspectiva dialética, uma dimensão histórica, em franca ruptura com os ideais iluministas, que estimavam um aperfeiçoamento linear, progressivo e a-histórico do desenvolvimento humano (SGADARI PASSEGGI, 2011, p.154).
}

Furlanetto (2018) argumenta que os alunos universitários dos cursos de licenciatura narram suas trajetórias e experiências de vida para justificar suas escolhas para, assim, aproximarem-se dos contextos e da compreensão de sua própria prática, o que permite que abandonem, gradativamente, os discursos que não fazem parte ou não fazem sentido em relação aos saberes de que vão se apropriando; assim, apoiando-se naquilo que foi vivenciado, eles passam a ter um discurso próprio.

A profissão docente vem se universalizando ao longo dos anos e ganhando espaço nas discussões, todavia, como argumenta Sarti (2019), ela é incompleta e indireta, devendo-se ao fato de as práticas estarem associadas a uma típica educação secundária que contempla uma hierarquia social de baixo custo. Apesar dos arranjos e alcances que a legislação conseguiu superar nesta área, ainda existem escapes que fazem com que a formação profissional não seja atingida nos graus mais elevados da docência, causando rupturas no processo de formação. 
A autora enfatiza que a perspectiva da formação profissional é que o futuro profissional consiga atuar com uma visão prático-reflexiva, em uma dinâmica que seja mais próxima da realidade, a fim de favorecer o desenvolvimento de suas competências para tal. Todavia, os cursos de formação estão trabalhando de modo que seus estudantes acumulem conhecimentos e nem sempre caminhem nesta direção.

Na perspectiva de Paniago e Sarmento (2015), os saberes construídos ao longo da formação docente não influenciam diretamente as práticas educativas, pois os conflitos existentes no cotidiano escolar são bem mais complexos, vai além dos campos disciplinares, da dialogicidade, do imaginário, da afetividade: são situações que ganham vida na história dos professores e alunos.

Escolher faz parte da vida humana. Decidir aquilo que realmente se deseja seguir. Mas a formação inicial não consegue dar conta de todo o conhecimento que deve ter o professor, pois ele está em constante transformação. Assim, cabe a ele, no processo da docência, escolher os saberes e as práticas necessárias para o enfrentamento do ofício.

Por outro lado, Sá e Santos (2016) fazem um levantamento relativo às razões de se escolher não ser professor e encontram a desmotivação, a desvalorização da profissão, as altas jornadas de trabalho e os baixos salários, o que leva os sujeitos a desacreditarem da profissão, não apresentarem interesse em serem licenciados, o que permite-nos entender que a carreira é um desafio em decorrência das condições que lhe são atribuídas.

Os dilemas sobre a escolha da profissão ficam mais claros conforme passam os anos, pois o confronto com a realidade desmotiva o docente. Assim, a identidade docente fica alterada, requerendo que o sujeito faça uma retomada, uma reflexão, para encontrar e dar sentido à docência.

\section{Saber docente em sua formação}

Segundo pesquisas realizadas, os movimentos autobiográficos relacionados à formação de professores acontecem desde a década de 90 e, para Passeggi, Souza e Vicentini (2011), eles se justificam, pois, ao narrar o seu percurso, o docente vai constituindo a sua identidade profissional, já que, no processo, conseguem atingir dimensões que vão além daquelas propiciadas pelas instituições.

Para além das narrativas, é fundamental o registro da biografia, para que se possa refletir sobre o que ali está descrito com um olhar mais intenso e seguro, para se dar forma à consciência histórica do indivíduo, o que permite que adentre territórios inimagináveis de aprendizagem. A construção identitária decorre, dessa forma, de um processo que se inicia na graduação e vai se modificando, ou adensando, de acordo com a trajetória do sujeito, não tendo um fim próximo e indo além, na busca de conexões com aquilo que condiz com sua formação. 
Abrahão (2011) caracteriza as memórias e recordações que estudantes de Pedagogia relatam ao descreverem os seus percursos de vida e as escolhas pela docência como fator atuante em seus modos de agir no magistério, que ensejam

[...] compreensões que, partindo do conjunto das narrativas, tanto no que possui de singular como de plural, atinjam abstrações capazes de permitirem compreensões mais aguçadas sobre processos de formação dos sujeitos, quer da própria formação, quer da formação de seus futuros alunos e das consequências dessa formação para cada um e para o contexto do social em que cada vida está inserida. (ABRAHÃO, 2011, p.170)

Filho (2011) expande a ideia do saber docente a partir da contínua formação do sujeito, que vai desde o ensino fundamental até chegar à universidade, uma etapa repleta de descobertas que acaba por propiciar reflexões de passado e de futuro sobre as projeções de conquistas, pensamentos e ideologias que, com o avanço das experiências, permitem uma melhor compreensão por conta do conhecimento oriundo daquela formação.

Quando relatado sobre a fragmentação de ensino perante a educação básica, fica muito claro que, se o aluno universitário não tiver uma formação concreta e sólida, capaz de elencar os conhecimentos e saberes ali propostos e construídos, o futuro apenas vai reservar a seus alunos a continuidade da desintegração do ensino, causando um círculo vicioso educacional.

Tardif (2001) argumenta que entre a função do professor e as especificidades do trabalho docente no cotidiano escolar há um espaço a ser superado, mas a universidade não consegue articular os conhecimentos trabalhados na formação inicial com aqueles necessários na ação profissional.

O autor faz uma relação do saber docente com o trabalho atribuído nas funções do professor em torno das especificidades do cotidiano, que por muito tempo já se estuda e enfoca a relação dos cursos de formação articulados com os conhecimentos desenvolvidos na prática docente, observando que, até o momento, a formação advinda da universidade não consegue estabelecer relação com a prática do professor.

Nunes (2001) considera que, para a compreensão da prática pedagógica do professor, tanto na sua atuação docente quanto na formação, é necessário refazer sua trajetória de vida, refletindo sobre suas experiências e percursos formativos, legitimando, dessa forma, a profissão, ao destacar a sua importância para resgatar o papel do professor em sua totalidade, em um ensino que vai além da academia e que agrega parâmetros pessoais, profissionais e organizacionais.

Quando o estudante inicia sua formação na universidade, ele ainda não faz ideia de todo o conhecimento que lhe será atribuído por aquela instituição, mas tem a conviç̧ão de que o conhecimento não acaba por ali, que é apenas um começo, e, por esses caminhos, vai agrupando informações, conceitos e pensamentos, construindo gradativamente sua identidade. 
Alves (2007), em seus estudos, discute a formação inicial em acordo com a concepção do professor reflexivo, identificando duas vertentes: o pensamento ideológico, que acaba por mascarar algumas realidades; e o princípio teórico, que visa aprofundar o saber para potencializar o ensino e dialogar com as diversas teorias.

A complexidade do estudo sobre identidades vai além de períodos e concepções, pois o sujeito é formado dentro de teorias e situações sociais de sua própria época, que com o passar do tempo, se esbarram dentro dos muros das escolas, com atitudes, ideias e conflitos que reúnem gerações de conhecimento.

Gimenez e Da Silva (2018) ressaltam que o debate que cerca a formação docente requer a formulação de teorias para a construção de um novo paradigma, que exige um professor flexível, com capacidade de solucionar problemas e de se adaptar a diferentes situações. Propõem, contudo, um programa de formação que conduza à visão de complexidade perante o modelo sistêmico, desde a matriz, até as metodologias e a avaliação. Os autores sugerem, ainda, uma reformulação do currículo, o que implica na amplitude e universalização do conhecimento e em considerar a linearidade, a dissociabilidade e a completude dessas aprendizagens como de suma relevância para a formação do sujeito.

\section{A identidade no saber docente}

Sá e Santos (2016) se atentam que a inter-relação entre o que é do sujeito e o que é de sua constituição social, sendo fundamental que os aspectos socioculturais sejam considerados neste processo.

Aparecida, Klebis e Gebran (2017) definem que, na constituição da identidade docente, a representação social exerce grande influência desde a formação inicial, exercendo orientações, condutas e práticas na sociedade, que tem propósitos educacionais, em especial para a escola pública.

Todo elemento constituído durante a vida, dessa forma, emerge à luz de informações, valores, ideias, opiniões, ou seja, de um estado de realidade relacionado ao saber que consegue transmitir. A ideia está situada em múltiplos contextos que perpassam um processo de autorreconhecimento, considerando o sujeito e suas transformações ocorridas no campo da intersubjetividade, em um processo de evolução constante tanto de si como dos diferentes contextos inseridos (APARECIDA; KLEBIS; GEBRAN, 2017).

Nakagome (2012) afirma que todo saber deve ser valorizado, porém, para que isso ocorra, os cursos de formação devem trazer a temática em discussão e não se limitar ao assunto, considerando a experiência pessoal e profissional do indivíduo. 
Diniz e Gimenez (2016) argumentam que a construção da identidade docente perpassa por todos os períodos da vida e vai se constituindo a partir de das experiências em diferentes períodos de vida e, especialmente, é decorrente daquelas associadas às vivências escolares. Sendo assim, a constituição da identidade profissional é um projeto em construção.

De acordo com Diniz e Gimenez (2016), que retratam o indivíduo como um sujeito encarnado, definido com base na sua preparação profissional, este enquanto começo, meio e fim quando analisado na perspectiva de pesquisador, mas que em sua formação distingue uma história inacabada que se inicia bem antes da constituição da vida e perpassa por toda uma trajetória de infância, fase adulta e percorre pelos caminhos da profissão, esbarrando com dilemas que buscam soluções por meio de respostas que a própria subjetividade abarca em seus estudos, porém coloca a experiência presente e ativa na formação do indivíduo, pois as ações de suas práticas são representadas, inclusive, através do corpo, que por sua vez está atrelado a um sujeito historicizado que compõe a formação profissional.

O saber é inacabado, das interações ocorridas ao longo da vida emergem verdades absolutas que transitam em uma sociedade viva, constituída por múltiplos saberes que vão se moldando e transformando conforme as vivências acontecem. O ofício de lecionar é bastante complexo e, por muitos anos, foi negligenciado, porém, políticas públicas estão sendo discutidas a fim de elevar o ensino e de garantir uma boa formação a todos, pois o saber se encontra em inúmeras áreas do conhecimento.

\section{Considerações finais}

Ao final do trabalho, verifica-se que a complexidade relativa ao processo de escolha da carreira docente no Brasil parece ser entendida em uma visão simplificada ou simplista, na maioria das vezes, partindo de relações de causa e efeito, identificadas em geral, como decorrentes do processo de formação. Todavia, requer ser analisada a partir de uma perspectiva mais abrangente, que considere a constituição do sujeito e a sua história em relação às vivências escolares antes da graduação. Do mesmo modo que a escolha do sujeito por um curso de formação de professores, a sua permanência é pautada pela dinâmica do curso e pelas construções realizadas no decorrer do processo. É necessário, assim, considerar que o fator de maior contribuição para a construção da identidade profissional do sujeito é o seu vínculo com a escolha feita.

As crises e os dilemas quanto à profissionalização surgem principalmente no início da graduação, pois o aluno adentra ao curso com muitas expectativas, mas trazendo consigo um saber anterior, o qual vai ser questionado, discutido, pensado e transformado e, conforme as vivências, 
os diálogos e as reflexões tomam forma no processo, tornam-se mais significativas na constituição da identidade docente.

As práticas vão sendo relatadas e deixam transparecer angústias e sentimentos em narrativas complexas e únicas de profissionais que encaram este ofício com vitalidade e vontade de fazer o melhor, porém, não deixam de desempenhar aquilo para que foram formados, mesmo tendo consciência da situação atual da carreira, com desvalorização, duplas ou triplas jornadas, baixos salários, enfim, que são situações degradantes para qualquer profissional.

Os desafios inseridos na profissão, contudo, fazem com que o professor vá se constituindo mediante as ocorrências em sua trajetória docente, mas a construção de sua identidade docente também está atrelada a constituição do ser humano, um ser cultural, envolvido socialmente com situações globais que perpassam família, amigos, etnia, em um contexto mais amplo.

Cabe concluir que o conhecimento é inacabado: sempre existe algo para aprender e, com isso, a constituição da identidade profissional, marcada por trocas, reflexões e conflitos que contribuem para a solidificação desta construção aberta, é um movimento contínuo de formação. Em suma, cabe analisar a origem dos diferentes contextos em que o aluno está inserido para que se possa compreender as suas concepções.

Os estudos sobre a constituição da formação docente são muito frequentes, todavia, rupturas e fragmentações persistem, faltando demandas a serem discutidas no âmbito educacional que possam direcionar a um caminho mais humanizado, com matrizes que possam agregar e direcionar ao contexto real das instituições de ensino, deixando de lado paradigmas e modelos padronizados que ainda são seguidos, superando o distanciamento entre teoria e prática e levando a perspectivas inovadoras de formação que contemplem ações pautadas em um processo reflexivo e dialógico.

Os caminhos a serem traçados partem, portanto, de uma reflexão acerca do processo contínuo de formação, uma vez que tal prosseguimento se expande para além dos muros das universidades e se coloca nos ambientes profissionais, pautado por discursos que representam a continuidade desta formação, favorecendo, porém, apenas uma pequena parte de um todo que compete a grande área educacional, que se justifica pelas narrativas de contexto pessoal e social e que se ampliam ou se reformulam no processo de formação inicial.

É necessário, contudo, que as formações sejam constituídas por matrizes que se aproximem do real, com metodologias e abordagens que se aplicam atualmente, sendo necessários estudos que possibilitem uma reflexão mais aprofundada, partindo da revisitação de teorias que possam subsidiar a complexidade do assunto, levando o estudante a expandir seu olhar educacional, 
amparado na subjetividade de sujeito histórico, marcado pelas incertezas e incongruências que só o tempo consegue mostrar e modificar, traçando um caminho de invenção e reinvenção.

\section{Referências}

ABRAHÃO, M. H. M. B. Memoriais de formação: a (re)significação das imagenslembranças/recordações-referências para a pedagoga em formação. Educação, v. 34, n. 2, 14 jul. 2011. Disponível em: https://revistaseletronicas.pucrs.br/ojs/index.php/faced/article/view/8708. Acesso em: 29 mai. 2021.

ALVES, W. F. A formação de professores e as teorias do saber docente: contextos, dúvidas e desafios. Educ. Pesqui., São Paulo, v. 33, n. 2, p. 263-280, Aug. 2007. Disponível em:

http://www.scielo.br/scielo.php?script=sci_arttext\&pid=S151797022007000200006\&lng=en\&nrm=iso. Acesso em: 02 fev. 2021. http://dx.doi.org/10.1590/S1517-97022007000200006.

APARECIDA, M.; KLEBIS, A. B. S. O.; GEBRAN, R. A. O papel das representações sociais na construção da identidade docente. Colloquium Humanarum. ISSN: 1809-8207, [S. l.], v. 14, n. 1, p. 86-96, 2017. Disponível em: http://journal.unoeste.br/index.php/ch/article/view/1924. Acesso em: 9 mar. 2021.

BRASIL. Lei no. 9.394, de 20 de dezembro de 1996. Estabelece as diretrizes e bases da educação nacional. Diário Oficial [da] União, Poder Executivo, Brasília, DF, 23 de dezembro de 1996. Disponível em: http://www.planalto.gov.br/ ccivil_03/_LEIS/19394.htm. Acesso em: 28 jan. 2021.

FILHO, W. H. Velhas histórias coladas à pele: a importância das histórias de vida na formação do professor. Educação, v. 34, n. 2, 14 jul. 2011.

FURLANETTO, E. C. Tomar a palavra: uma possibilidade de formação. Revista@mbienteeducaşão, [S.l.], v. 2, n. 2, p. 128 - 135, mar. 2018. ISSN 1982-8632. Disponível em:

http://publicacoes.unicid.edu.br/index.php/ambienteeducacao/article/view/559. Acesso em: 28 jan. 2021.

GIMENEZ, R.; DA SILVA, M. H. A. Formação de professores para a educação básica: revisitando concepções e práticas pedagógicas por meio do prisma de teorias da complexidade. Revista@mbienteeducação, [S.1.],v. 7, n. 2, p. 268 - 276, jan. 2018. ISSN 1982-8632. Disponível em: https://publicacoes.unicid.edu.br/index.php/ambienteeducacao/article/view/481/457. Acesso em: 29 mar. 2021.

DINIZ, L. T.; GIMENEZ, R. A construção do docente encarnado na experiência da ação corporal: perspectivas para a preparação profissional para a educação infantil. Horizontes, v. 34, n. 2, p. 85 - 92, 21 dez. 2016.

LOPES, L. P. S. Identidade docente na educação infantil: Marcas da formação e das experiências profissionais no contexto das instituições. 2015. 156f. Dissertação (Mestrado em Educação) Programa de Pós-Graduação em Educação, Centro de Ciências Humanas e Sociais Aplicadas, Faculdade de Educação, Pontifícia Universidade Católica de Campinas, Campinas, 2015. 
NAKAGOME, P. T. Identidade docente em formação. Linha D'Água, [S. l.], v. 25, n. 1, p. 203217, 2012. DOI: 10.11606/issn.2236-4242.v25i1p203-217. Disponível em: https://www.revistas.usp.br/linhadagua/article/view/37373. Acesso em: 9 mar. 2021.

NÓVOA, A. Profissão professor. In: NÓVOA, A. O passado e o presente dos professores. Tradução: Irene Lima Mendes, Regina Correia, Luisa Santos Gil. Ed. Porto: Porto, 1999, p. 13-34.

NUNES, C. M. F. Saberes docentes e formação de professores: um breve panorama da pesquisa brasileira. Educ. Soc., Campinas, v. 22, n. 74, p. 27-42, 2001. Disponível em:

http://www.scielo.br/scielo.php?script=sci_arttext\&pid=S0101-

$73302001000100003 \& \operatorname{lng}=$ en\&nrm=iso. Acesso em: 02 fev. 2021.

https://doi.org/10.1590/S0101-73302001000100003.

PANIAGO, R. N.; SARMENTO, T. J. O processo de estágio supervisionado na formação de professores portugueses e brasileiros. Revista Educação em Questão, Natal, v. 53, n. 39, p. 76-103, set./dez. 2015.

PASSEGGI, M. C.; SOUZA, E. C.; VICENTINI, P. P. Entre a vida e a formação: pesquisa (auto)biográfica, docência e profissionalização. Educ. rev. Belo Horizonte, v. 27, n. 1, p. 369-386, Apr. 2011. Disponível em: http:/ / www.scielo.br/scielo.php?script=sci_arttext\&pid=S010246982011000100017\&lng=en\&nrm=iso. Acesso em: 01 fev. 2021.

https://doi.org/10.1590/S0102-46982011000100017.

SÁ, C. S. S.; SANTOS, W. L. P. Motivação para a carreira docente e construção de identidades: o papel dos pesquisadores em ensino de química. Quím. Nova, São Paulo, v. 39, n. 1, p. 104-111, Jan. 2016. Disponível em: http://www.scielo.br/scielo.php?script=sci_arttext\&pid=S010040422016000100104\&lng=en\&nrm=iso. Acesso em: 01 fev. 2021.

https://doi.org/10.5935/0100-4042.20150155.

SARTI, F. M. O curso de pedagogia e a universitarização do magistério no Brasil: das disputas pela formação docente à sua desprofissionalização. Educ. Pesqui, São Paulo, v. 45, e190003, 2019. Disponível em: http://www.scielo.br/scielo.php?script=sci_arttext\&pid=S151797022019000100540\&lng=en\&nrm=iso. Acesso em: 22 jan. 2021. Epub May 09, 2019. https://doi.org/10.1590/s1678-4634201945190003.

SGADARI PASSEGGI, M. da C. B. A experiência em formação. Educação, v. 34, n. 2, 14 jul. 2011. Disponível em:

https://revistaseletronicas.pucrs.br/ojs/index.php/faced/article/view/8697. Acesso em: 29 mai. 2021.

TANURI, L. M. História da formação de professores. Rev. Bras. Educ. Rio de Janeiro, n. 14, p. 61-88, Aug. 2000. Disponível em:

http://www.scielo.br/scielo.php?script=sci_arttext\&pid=S1413-

24782000000200005\&lng=en\&nrm=iso. Acesso em: 23 mai. 2021.

TARDIF, M. O trabalho docente, a pedagogia e o ensino: interações humanas, tecnologias e dilemas. Educ. FaE/UFPel, Pelotas (16): 15 - 47, jan./jun. 2001. Disponível em:

https://periodicos.ufpel.edu.br/ojs2/index.php/caduc/article/download/6594/4578. Acesso em: 29 mai. 2021. 